\title{
Validation method for determining enrofloxacin and tylosin levels in broiler liver, kidney, and muscle using high-performance liquid chromatography
}

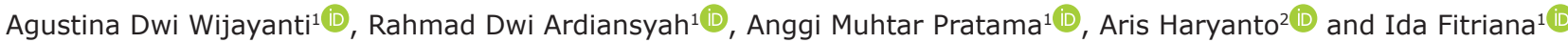 \\ 1. Department of Pharmacology, Faculty of Veterinary Medicine, Universitas Gadjah Mada, Jl. Fauna no. 2 Karangmalang, \\ Yogyakarta, Indonesia; 2. Department of Biochemistry, Faculty of Veterinary Medicine, Universitas Gadjah Mada, Jl. \\ Fauna no. 2 Karangmalang, Yogyakarta, Indonesia. \\ Corresponding author: Agustina Dwi Wijayanti, e-mail: tinabdy@ugm.ac.id \\ Co-authors: RDA: rahmad.dwi.a@mail.ugm.ac.id, AMP: anggi.muhtar.p@mail.ugm.ac.id, AH: arisharyanto@ugm.ac.id, \\ IF: ida.fitriana@ugm.ac.id
}

Received: 27-08-2021, Accepted: 10-01-2022, Published online: 08-02-2022

doi: www.doi.org/10.14202/vetworld.2022.268-274 How to cite this article: Wijayanti AD, Ardiansyah RD, Pratama AM, Haryanto A, Fitriana I (2022) Validation method for determining enrofloxacin and tylosin levels in broiler liver, kidney, and muscle using high-performance liquid chromatography, Veterinary World, 15(2): 268-274.

\begin{abstract}
Background and Aim: Enrofloxacin and tylosin can be combined into an antibiotic formulation which is expected to have a broader range of antibacterial activity against various infections in broilers. Validation method analysis of the levels of these two active compounds needs to be done for future use in pharmacokinetic or residual studies. The present study aims to determine a suitable validation method of isocratic high-performance liquid chromatography (HPLC) to measure the concentration of antibiotic combinations in the broiler liver, kidney, and muscles.

Materials and Methods: The combination of enrofloxacin and tylosin in the liver, kidney, and muscle was validated by HPLC method to find the procedures, processes, equipment, and systems used, consistently provides the appropriate results. The chromatography system consisted of an Octadecyl-silica column of $5 \mu \mathrm{m}$ in diameter and $150 \mathrm{~mm}$ in length with a mobile phase of a mixture of $0.05 \mathrm{M}$ monobasic sodium phosphate $(\mathrm{pH} 2.5)$ and acetonitrile $(65: 35 \mathrm{v} / \mathrm{v})$. The solution was detected at a wavelength of $280 \mathrm{~nm}, 30^{\circ} \mathrm{C}$, a flow rate of $1 \mathrm{~mL} / \mathrm{min}$, and an injection volume of $20 \mu \mathrm{L}$. The combination antibiotics powder was produced from PT Tekad Mandiri Citra, Bandung, Indonesia, and broiler tissues obtained from dayold chick broilers maintained for 30 days with free antibiotic feed.

Results: Validation of a combination solution of enrofloxacin and tylosin shows the linearity values of enrofloxacin and tylosin in the liver, kidney, and muscles as $r^{2}=0.9988, r^{2}=0.9999, r^{2}=0.9997, r^{2}=0.9989, r^{2}=0.9978$, and $r^{2}=0.9962$. The accuracy and precision values of enrofloxacin in the liver, kidney, and muscles were 5.53, 6.23, and 6.93, respectively. The values of accuracy and precision of tylosin in the liver, kidney, and muscles were 10.43, 4.63, and 7.16\%, respectively. The retention times for enrofloxacin and tylosin were 1.945-2.000 $\mathrm{min}$ and 4.175-4.342 min. The limit of detection (LOD) and limit of quantity (LOQ) values for enrofloxacin were 3.03 and $10.1 \mu \mathrm{g} / \mathrm{g}$, respectively. In contrast, the LOD and LOQ values for tylosin were 9.05 and $30.17 \mu \mathrm{g} / \mathrm{g}$, respectively.
\end{abstract}

Conclusion: The value of linearity, accuracy, precision, specificity, and sensitivity of the combined solution of enrofloxacin and tylosin showed promising results.

Keywords: enrofloxacin-tylosin combination, high-performance liquid chromatography, validation method.

\section{Introduction}

Broiler farms are generally susceptible to viral, bacterial, fungal, and parasitic infections which might increase due to poor quality environmental conditions [1,2]. Suitable antibiotic therapies are used to treat infections caused by Gram-positive and Gramnegative bacteria [3-5]. Enrofloxacin is a potent antibiotic having bactericidal action by affecting bacterial DNA topoisomerase [6-8]. Several bacteria such as Mycoplasma gallisepticum and Mycoplasma synoviae have been reported to be resistant to

Copyright: Wijayanti, et al. Open Access. This article is distributed under the terms of the Creative Commons Attribution 4.0 International License (http://creativecommons.org/licenses/ by/4.0/), which permits unrestricted use, distribution, and reproduction in any medium, provided you give appropriate credit to the original author(s) and the source, provide a link to the Creative Commons license, and indicate if changes were made. The Creative Commons Public Domain Dedication waiver (http:// creativecommons.org/publicdomain/zero/1.0/) applies to the data made available in this article, unless otherwise stated. enrofloxacin [9-11]. However, a combination of antibiotics can be used as an alternative to avoid antibiotic resistance. Tylosin is an antibiotic of macrolide group having bacteriostatic action that can bind to $23 \mathrm{~S}$ rRNA of the $50 \mathrm{~S}$ ribosomal subunit, thereby inhibiting protein synthesis. Moreover, they induce the dissociation of peptidyl-tRNA from the ribosome during translocation [12-14]. The combination of enrofloxacin and tylosin is expected to produce better effectiveness, especially in poultry therapy. Furthermore, this combination has been previously studied to check for any damaging effects on the liver and kidney. However, it is reported to be safe when administered at therapeutic doses [15].

Pharmacokinetic simulation can explain the retention of drugs in the body until excretion and can be used to determine residual levels per time unit. One of the analytical methods used for pharmacokinetic 
and residual studies is high-performance liquid chromatography (HPLC) [16]. Single-drug formulations in the body are usually determined by one HPLC validation method. HPLC validation methods need to be developed to measure the concentration of two or more compounds in broiler tissue [17]. Validation of analytical methods is a process of the procedures, systems, processes, materials, and tools so that if used, it would consistently provide the expected results. Validation of analytical methods is an act of parameter assessment to obtain a standard in the test of an ingredient. Some of the analysis parameters are accuracy, precision, selectivity, linearity, the limit of detection (LOD), and quantity (LOQ).

This study aimed to validate the HPLC analysis method for determining concentrations of a combination of enrofloxacin and tylosin in vitro in the liver, kidney, and muscles of the broiler using a validated analytical method.

\section{Materials and Methods}

\section{Ethical approval}

The study was approved by Ethics Commission of the Faculty of Veterinary Medicine, Gadjah Mada University (Approval number 0042/EC-FKH/ Int/2019).

\section{Study period, area, and procedure}

The study was conducted from September 2019 until February 2020 in Pharmacology Laboratory and study center of animal, Faculty of Veterinary Medicine Gadjah Mada University. Methods include treating animals and tissues sampling, preparing the standard curve of tylosin-enrofloxacin formulation in the mobile phase and drug spiking the liver, kidney, and muscles, and determining the value of the analyzed parameters. The combination product consisted of $125 \mathrm{mgtylosin}$ tartrate and 125 mgenrofloxacin $\mathrm{HCl}$ in $1000 \mathrm{mg}$ powder of formulation and was obtained from PT Tekad Mandiri Citra, Bandung, Indonesia. Analysis of the concentration of tylosin-enrofloxacin as serial concentration from stock solution and in the liver, kidneys, and muscle samples was carried out using the HPLC tool (Shimadzu version 6.1, Tokyo, Japan) based on the Animal Drug Residue Analysis method [5,18-20].

\section{Animal handling and sampling}

Three broilers were kept in postal pens of experimental animals starting from day-old chicken and given antibiotic-free BR-1 feed and ad libitum drinking water. After 30 days of age, broilers weighing $1-1.5 \mathrm{~kg}$ were slaughtered by halal slaughter method, then dissected. The liver, kidneys, and muscles were collected and stored in a freezer until analysis on the HPLC equipment. The broiler tissues used in spiking analysis measure the drug concentration from blank sample tissues.

The mobile phase construction and HPLC preparation

The HPLC tool was set at a temperature of $30^{\circ} \mathrm{C}$, a detector at a wavelength of $280 \mathrm{~nm}$, and a flow rate of $1 \mathrm{~mL} / \mathrm{min}$. The mobile phase used is a mixture of $0.05 \mathrm{M}$ monobasic sodium phosphate $(\mathrm{pH} 2.5)$ and acetonitrile in the ratio of $65: 35 \mathrm{v} / \mathrm{v}$. The mobile phase mixture was adjusted to $\mathrm{pH} 2.5$ by adding a few drops oftriethylamine (Merck KGaA, Darmstadt, Germany).

\section{Tissue sample extracts production}

Analysis of the concentration of enrofloxacin-tylosin in the liver, kidney, and muscle samples was by first extracting tissue using a modified method of Widiastuti [20]. The liver, kidney, and muscles were chopped and crushed until smooth; each was weighed as much as $1 \mathrm{~g}$ and put in acentrifuge tube (Corning ${ }^{\circledR}$, Merck, Germany) then $2.5 \mathrm{~mL}$ of $1 \%$ acetonitrile acid $(1 \mathrm{~mL}$ of acetic acid anhydrous in $100 \mathrm{~mL}$ acetonitrile; J.T. Baker, Solusorb, USA) were added. The samples and chemicals were then vortexed for $5 \mathrm{~min}$ and centrifuged at $3000 \times \mathrm{g}$ for $10 \mathrm{~min}$. The supernatant was separated and kept in a water bath for $10 \mathrm{~min}$. After drying, $1.5 \mathrm{~mL}$ phosphate buffer $(\mathrm{pH} 7.4)$ and $2 \mathrm{~mL}$ $\mathrm{N}$-hexane were added; it was mixed with vortex for $5 \mathrm{~min}$ and centrifuged at $3000 \times g$ for $10 \mathrm{~min}$. Then, the supernatant was taken, hexane was removed, and the procedure was repeated thrice. The collective supernatant obtained was then centrifuged at $2500 \times g$ for $15 \mathrm{~min}$, then filtered, and injected into HPLC as much as $20 \mu \mathrm{L}$. The concentration of enrofloxacin-tylosin in the liver, kidney, and muscles was estimated to create a standard curve of the drug in the tissue.

\section{Building enrofloxacin-tylosin standard curves in the liver, kidney, and muscles}

The standard curve of the combined solution was first prepared by injecting serialconcentrations diluting of 10,50 , and $100 \mu \mathrm{g} / \mathrm{mL}$ from stock solution $1 \mathrm{mg} / \mathrm{mL}$ into the HPLC system. The standard curves of the drug in the liver, kidney, and muscle samples were then made by spiking the drug in the sample blank. The results of the extraction of a blank sample of liver, kidney, and muscle were combined with a standard solution of enrofloxacin-tylosin with the concentrations of 10,50 , and $100 \mu \mathrm{g} / \mathrm{g}$, respectively. To obtain a linear line equation, each concentration was injected as much as $20 \mu \mathrm{L}$ with three repetitions. The standard curve was created for the peak area of each drug concentration.

\section{Determination of the value of accuracy, precision, specificity, and sensitivity of the HPLC method}

The accuracy and precision values of the analysis method were used to prepare the standard curve of enrofloxacin in the liver, kidneys, and muscles using the method above. The accuracy value ( $\%$ recovery) is calculated by dividing the measured concentration by the actual concentration multiplied by $100 \%$. The precision value is expressed by the coefficient of variation $(\mathrm{CV} \%)$, which is calculated to compare standard deviations with the average measured concentration multiplied by $100 \%$ [21].

Specificity was determined by observing at the peak area profile and retention time on the 
chromatogram of the standard solution of enrofloxacin-tylosin (concentration 10, 50, and $100 \mu \mathrm{g} / \mathrm{g}$ ) and comparing the chromatogram blank and spiking the standard solution of a tylosin-enrofloxacin concentration of $10 \mu \mathrm{g} / \mathrm{g}$ in the liver, kidney, and muscles.

The sensitivity of the HPLC is determined by setting LOQ and LOD values. The limit of quantification is the smallest number of analytes in a sample that still meets the particular criteria. At the same time, the LOD is the smallest number of analytes in a sample that can still be detected even though it could not always be quantified and gives a significant response compared to the blank [21].

\section{Results}

The validation of the method of determining the levels of enrofloxacin and tylosin in the liver, kidneys, and muscles using HPLC was performed to see linearity, accuracy, precision, specificity, and sensitivity [22-24]. Before drug spiking in tissues, the standard stock solution of drug formulation was carried out to find the linearity of three different concentrations $(10,50$, and $100 \mu \mathrm{g} / \mathrm{g})$. The chromatogram showed separated peaks of retention times of enrofloxacin and tylosin as 1.945-2.000 and 4.1754.342 min, respectively (Figures-1 and 2). The standard equations of the enrofloxacin and tylosin curves in the liver, kidneys, and muscles are $\mathrm{Y}=\mathrm{bx}+\mathrm{a}$, with $\mathrm{R}^{2}$, the coefficient of determination, and $\mathrm{r}$, the coefficient of correlation. Equations of enrofloxacin curve were $=42,258 \mathrm{x}+2,178,206$ and $\mathrm{R}^{2} 0.9988$ (liver), $\mathrm{Y}=211,717 \mathrm{x}+5,246,737$ and $\mathrm{R}^{2} 0.9999$ (kidney), and $\mathrm{Y}=247,726 \mathrm{x}+3,340,928$ and $\mathrm{R}^{2} 0.9997$ (muscle), respectively, while the equations of tylosin curves were $\mathrm{Y}=1401.8 \mathrm{x}+26,140$ and $\mathrm{R}^{2} 0.9989$ (liver), $\mathrm{Y}=836.38 \mathrm{x}+35,711$ and $\mathrm{R}^{2} 0.9978$ (kidney), $\mathrm{Y}=1401.8 \mathrm{x}+26,140$ and $\mathrm{R}^{2} 0.9962$ (muscle), respectively. The linearity graph of the combination of enrofloxacin and tylosin is shown in Figures-3 and 4.

The validation results showed that the accuracy value of enrofloxacin in the liver was $10 \mu \mathrm{g} / \mathrm{g}$ at $11.62 \%, 50 \mu \mathrm{g} / \mathrm{g}$ at $4.07 \%$, and $100 \mu \mathrm{g} / \mathrm{g}$ at $1.81 \%$. The validation results showed that the accuracy value of enrofloxacin in the kidney was $10 \mu \mathrm{g} / \mathrm{g}$ at $8.32 \%$, $50 \mu \mathrm{g} / \mathrm{g}$ at $6.49 \%$, and $100 \mu \mathrm{g} / \mathrm{g}$ at $3.71 \%$ and in muscle was $10 \mu \mathrm{g} / \mathrm{g}$ at $14.29 \%, 50 \mu \mathrm{g} / \mathrm{g}$ at $3.90 \%$, and $100 \mu \mathrm{g} / \mathrm{g}$ at $3.18 \%$, respectively.

The validation results showed that the accuracy of tylosin in the liver was $10 \mu \mathrm{g} / \mathrm{g}$ at $11.02 \%$, $50 \mu \mathrm{g} / \mathrm{g}$ at $10.19 \%$, and $100 \mu \mathrm{g} / \mathrm{g}$ at $10.78 \%$, in the kidney was $10 \mu \mathrm{g} / \mathrm{g}$ at $2.57 \%, 50 \mu \mathrm{g} / \mathrm{g}$ at $4.00 \%$, and $100 \mu \mathrm{g} / \mathrm{g}$ at $7.51 \%$, and in the muscle was $10 \mu \mathrm{g} / \mathrm{g}$ at $12.21 \%, 50 \mu \mathrm{g} / \mathrm{g}$ at $9.01 \%$, and $100 \mu \mathrm{g} / \mathrm{g}$ at $1.49 \%$. In addition to accuracy, the recovery value ( $\%$ recovery) is also calculated by comparing the measured concentration of enrofloxacin or tylosin with the actual level of enrofloxacin or tylosin multiplied by $100 \%$. The values of enrofloxacin recovery in the liver, kidney, and muscle were 92.39-125.88, 85.86-109.31, and $94.47-124.77 \%$, respectively. The values of tylosin recovery in the liver, kidney, and muscle were 82.17-124.86, 90.50-117.24, and 86.48-113.53\%, respectively.

The precision $(\mathrm{CV} \%)$ values of enrofloxacin in the liver, kidneys, and muscles were 5.53, 6.23, and $6.93 \%$, respectively. Precision values of tylosin in the liver, kidney, and muscles were 10.43, 4.63, and $7.16 \%$, respectively.

The results show that the specificity of enrofloxacin with the time of retention in the liver, kidney, and muscles was 1.950-2.000, 1.950-1.958, and 1.945-1.950 min, respectively. The specificity of tylosin with the time lease in the liver, kidney, and muscles, respectively, was as follows: 4.258-4.342, 4.175-4.342, and 4.208-4.242 min. The retention time and chromatogram peak between the two compounds were well separated.

The LOQ values of enrofloxacin in the liver, kidney, and muscles were $22.2,5.85$, and $10.1 \mu \mathrm{g} / \mathrm{g}$, respectively. The LOQ values of tylosin in the liver, kidney, and muscle were $21.32,30.17$, and $39.17 \mu \mathrm{g} / \mathrm{g}$, respectively. The LOD values of enrofloxacin in the liver, kidney, and muscles were 6.66, 1.76, and $3.03 \mu \mathrm{g} / \mathrm{g}$, respectively. The tylosin LOD values in the liver, kidney, and muscles were $6.39,9.05$, and $11.75 \mu \mathrm{g} / \mathrm{g}$, respectively.

\section{Discussion}

Our results demonstrated that HPLC UV detection $280 \mathrm{~nm}$ can be used to determine the concentration of enrofloxacin and tylosin. As per Ghanem and Abu-Lafi [25], the optimum wavelength of $287 \mathrm{~nm}$ was used to detect tylosin tartrate with a column temperature of $25^{\circ} \mathrm{C}$ and a flow rate of $1 \mathrm{~mL} / \mathrm{min}$. Based on the research of Karademir et al. [26], a wavelength of $280 \mathrm{~nm}$ was used for the detection of enrofloxacin. The peak of analyte (enrofloxacin and tylosin) was easy to identify from the impurities peak of other unknown substances in the feed matrix.

Linearity is indicated by the value of $r$ (correlation coefficient). The $r$ values of enrofloxacin in the liver, kidneys, and muscles were 0.9994, 0.9999, and 0.9999, respectively, while the $r$ values of tylosin in the liver, kidney, and muscles were $0.9999,0.9989$, and 0.9981 , respectively. Linear regression data showed good linearity for all the analytes with correlation coefficient (r) in the range of 0.998-0.999 [24]. The results of this study indicate an excellent linearity value $(r>0.9999)$ as in the study by Anacleto et al. [27].

The accuracy of the sample combination of enrofloxacin and tylosin was made in three standards with known concentrations of 10,50 , and $100 \mu \mathrm{g} / \mathrm{g}$. The validation results showed that the accuracy values of enrofloxacin and tylosin levels in the liver, kidney, and muscles were good. Based on the research of Yaneva et al. [28], the detection of tylosin using HPLC with a mobile phase composed of acetonitrile and $0.1 \mathrm{M} \mathrm{H} 3 \mathrm{PO} 4(60: 40, \mathrm{v} / \mathrm{v})$, flow rate to $0.8 \mathrm{~mL} / \mathrm{min}$, 


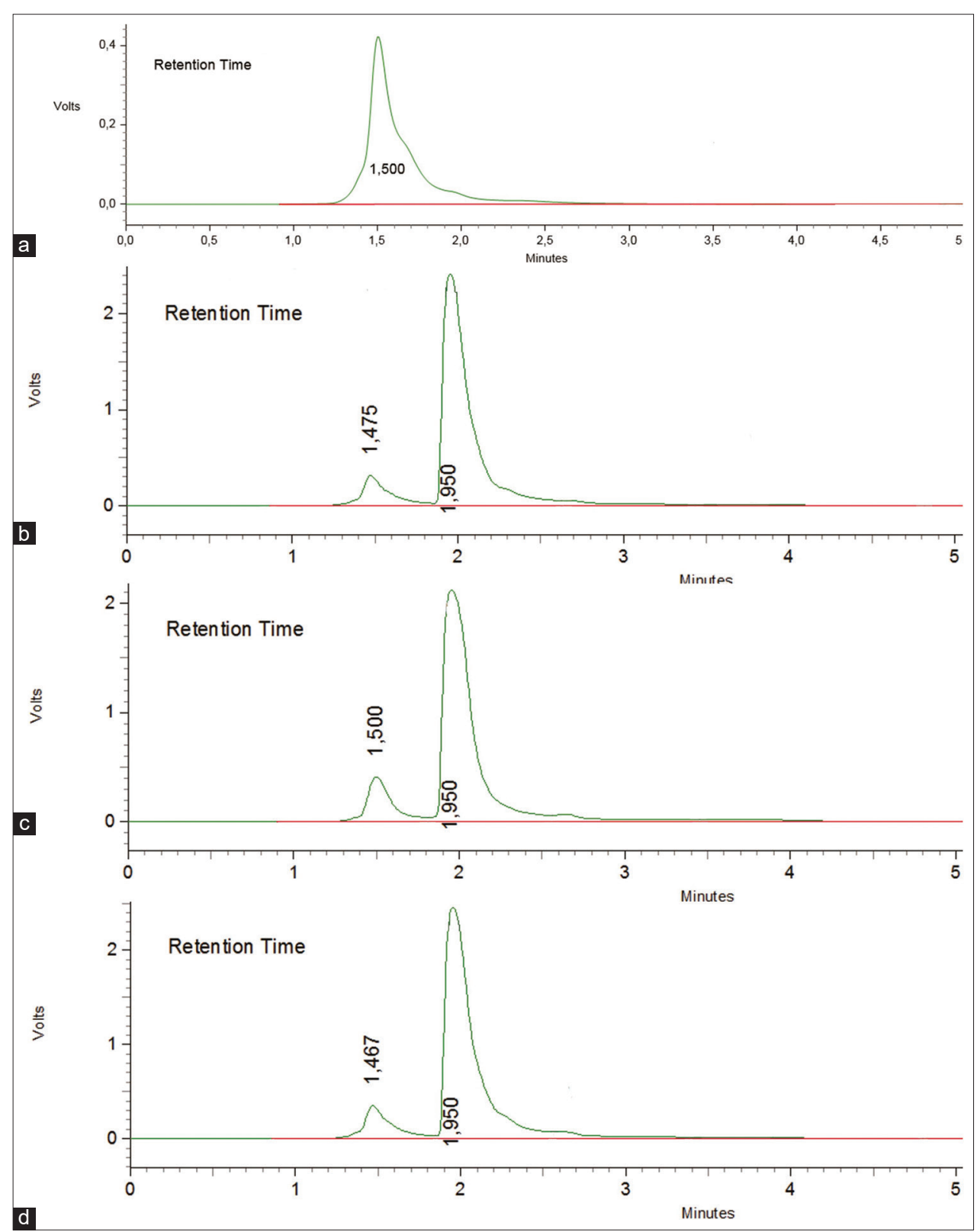

Figure-1: Standard enrofloxacin chromatogram. (a) Chromatogram blank (without drugs) muscle; (b) enrofloxacin spiking chromatogram concentration of $10 \mu \mathrm{g} / \mathrm{g}$ in the liver (retention time $1.950 \mathrm{~min}$ ); (c) enrofloxacin spiking chromatogram concentration of $10 \mu \mathrm{g} / \mathrm{g}$ in the kidney (retention time $1.950 \mathrm{~min}$ ); (d) enrofloxacin spiking chromatogram concentration of $10 \mathrm{\mu g} / \mathrm{g}$ in muscle (retention time $1.950 \mathrm{~min}$ ).

temperature $30^{\circ} \mathrm{C}$, and wavelength $290 \mathrm{~nm}$ showed an accuracy value of $0.89 \%$. An accuracy value of $<10 \%$ shows promising results for analyte testing. A study by Ancleto et al. [27] showed that enrofloxacin detection using HPLC with a mobile phase water and acetonitrile $(87: 13, \mathrm{v} / \mathrm{v})$ plus $0.1 \%$ trifluoroacetic acid, flow rate to $3 \mathrm{~mL} / \mathrm{min}$, and wavelength detection of $280 \mathrm{~nm}$ fetched an accuracy value of $0.45-1.1 \%$, the accuracy is good as the value is less than $10 \%$. According to Hakim [29], the accuracy of using the sample extraction method should be no less than $75 \%$ or a systematic value of no more than 25\%. Meanwhile, the accuracy received was $\pm 15 \%$, except for the LOQ value of $\leq 20 \%$. The accuracy and precision test results did not exceed $\pm 15 \%$ [30].

Good precision will produce repeated measurements at the same level with relatively low variation.
The precision (CV\%) values of enrofloxacin and tylosin in the liver, kidney, and muscles were good. The results of this study are in accordance with Chakravarthy et al. [31], with a CV\% value of $1.9 \%$ for the detection of enrofloxacin using HPLC. Tylosin tested by HPLC using a mobile was an isocratic combination of water: acetonitrile $(70: 30 ; \mathrm{v} / \mathrm{v})$ adjusted to $\mathrm{pH}$ of 5.5 using $0.1 \mathrm{~N}$ acetic acid, flow rate $1 \mathrm{~mL} / \mathrm{min}$, wavelength $287 \mathrm{~nm}$, and column temperature $25^{\circ} \mathrm{C}$ shows $\mathrm{CV}$ values $\%$ of $1.16 \%$, the value shows good results [24]. According to Lindholm [32], an analytical method for biological sample research was said to meet requirements if the $\mathrm{CV} \%$ was $\leq 15 \%$. The results of this study indicate that the $\mathrm{CV} \%$ is in accordance with the literature.

Specificity is the ability of an analytical method to carefully measure compounds that are measured 


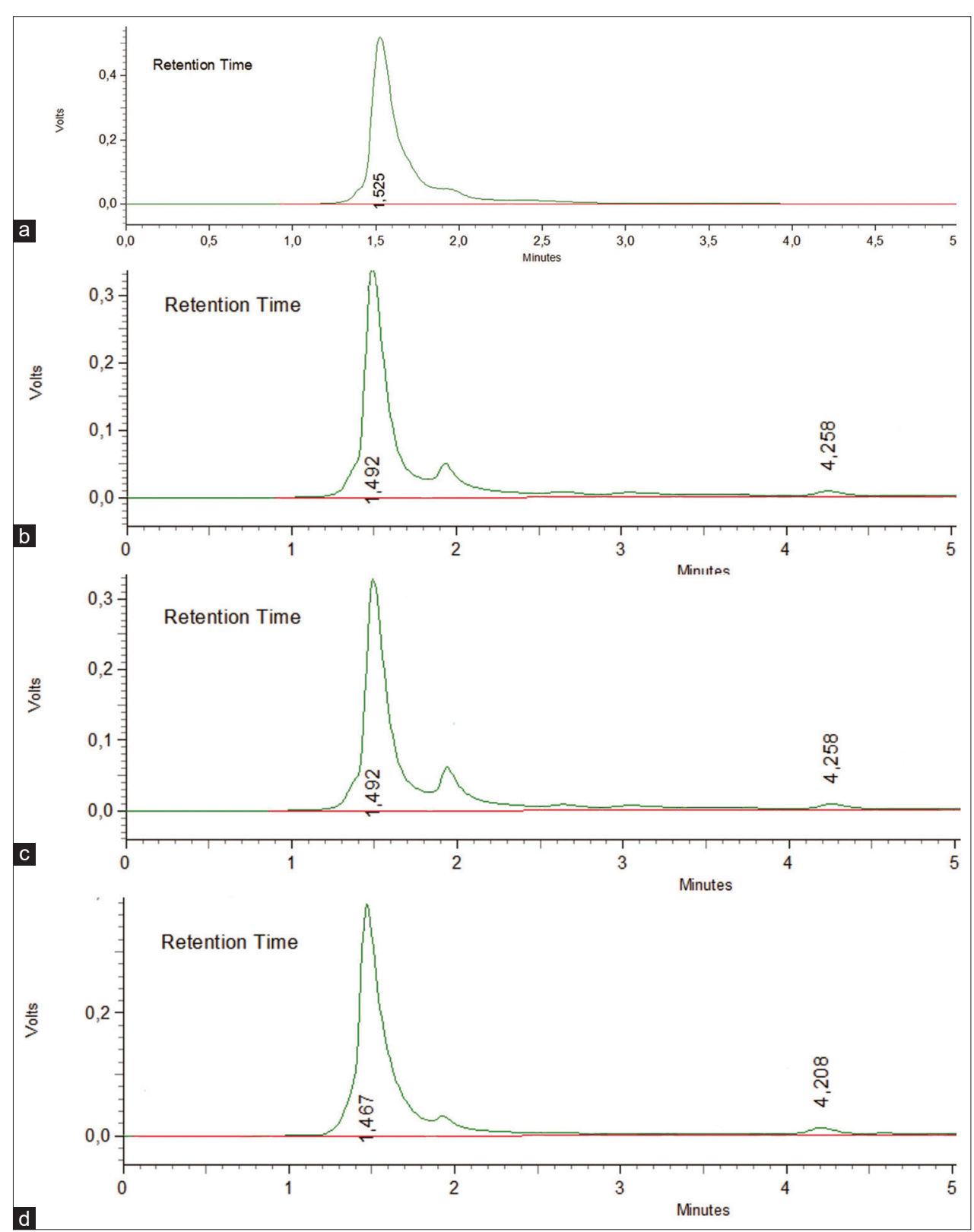

Figure-2: Standard tylosin chromatogram. (a) Chromatogram blank (without drugs) muscle; (b) tylosin spiking chromatogram concentration of $10 \mathrm{\mu g} / \mathrm{g}$ in the liver (retention time $4.258 \mathrm{~min}$ ); (c) tylosin spiking chromatogram concentration of $10 \mu \mathrm{g} / \mathrm{g}$ in the kidney (retention time $4.258 \mathrm{~min}$ ); (d) tylosin spiking chromatogram concentration of $10 \mu \mathrm{g} / \mathrm{g}$ in muscle (retention time $4.208 \mathrm{~min}$ ).

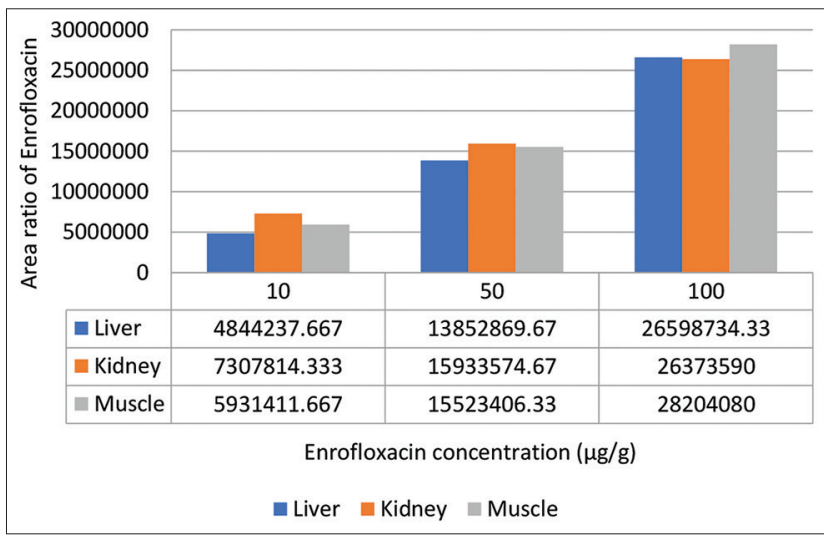

Figure-3: Enrofloxacin calibration graph for liver, kidney, and muscle with the concentration of $10 \mu \mathrm{g} / \mathrm{g}, 50 \mu \mathrm{g} / \mathrm{g}$, and $100 \mu \mathrm{g} / \mathrm{g}$. without interference from other compounds. The specificity of the analytical method in this study was determined by looking at the peak area profile on a blank chromatogram and spiking a standard solution of enrofloxacin and tylosin in the liver, kidney, and muscles. Chromatograms containing standard peak area profiles of enrofloxacin and tylosin at concentrations of 10,50 , and $100 \mu \mathrm{g} / \mathrm{g}$ are shown in Figures- 1 and 2.

The sensitivity of the test method in this study was determined by identifying the LOQ and LOD values. The LOQ is the smallest quantity of compounds in a sample that still meets the meticulous and criteria. At the same time, the LOD is the smallest amount of compound in a sample that can still be detected even 


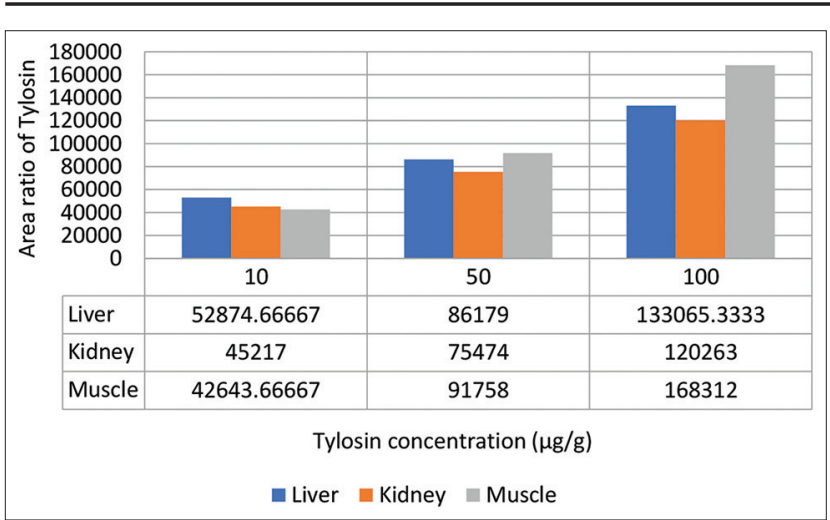

Figure-4: Tylosin calibration graph in liver, kidneys, and muscles with the concentration of $10 \mu \mathrm{g} / \mathrm{g}, 50 \mu \mathrm{g} / \mathrm{g}$, and $100 \mu \mathrm{g} / \mathrm{g}$

though it cannot always be quantified and gives a significant response compared to the blank $[32,33]$. Based on research by Ghanem and Abu-Lafi [25], the values of LOD and LOQ tylosin are 5.6 and $18.7 \mu \mathrm{g} / \mathrm{mL}$. Results of Moudgil et al. [23] detected enrofloxacin using HPLC with a mobile phase of methanol: acetonitrile $(75: 25, \mathrm{v} / \mathrm{v})$ with a gradient elution of $90: 10$ aqueous phase, a flow rate to $0.8 \mathrm{~mL} /$ min, and a column temperature of $27^{\circ} \mathrm{C}$ showing LOD values and LOQ of 18.9 and $57.3 \mathrm{ng} / \mathrm{mL}$. Based on research by Anacleto et al. [27], the LOD and LOQ values of enrofloxacin were 2.24 and $7.46 \mu \mathrm{g} / \mathrm{mL}$. The LOD and LOQ values in this study are not much different from the previous literature, which shows that the method in this study can be used to detect enrofloxacin and tylosin. According to the European Commission, maximum residue limits of enrofloxacin and tylosin are range from 100 to $300 \mu \mathrm{g} / \mathrm{kg}$ in broilers tissues $[1,2]$. The current study needs improvement for measuring LOQ and LOD values, as there are other limitations in measuring the residual value of these two drug compounds.

\section{Conclusion}

Optimum conditions for analysis of enrofloxacin and tylosin in the liver, kidneys, and muscles in vitro as a standard in HPLC using Octadecyl-silica columns are $5 \mathrm{~mm}$ in diameter and $150 \mathrm{~mm}$ length; mobile phase mixture of $0.05 \mathrm{M}$ monobasic sodium phosphate $(\mathrm{pH} 2.5)$ and acetonitrile in the ratio of $65: 35 \mathrm{v} / \mathrm{v}$; a temperature of $30^{\circ} \mathrm{C}$; wavelength of $280 \mathrm{~nm}$; and a flow rate of $1 \mathrm{~mL} / \mathrm{min}$. The validation results show that our bioanalysis method has fulfilled the criteria of linearity, accuracy, precision, specificity, and sensitivity in accordance with the provisions contained in the European Medicines Agency Guideline, and hence, it could be used for the analysis of a combination of enrofloxacin and tylosin in the liver, kidney, and muscles of broiler.

\section{Authors' Contributions}

ADW, IF, and AH: Designed the study. RDA, AMP, and IF: Field research and sample analysis in the laboratory. All authors wrote, edited, read, and approved the final manuscript.

\section{Acknowledgments}

The authors are thankful to Research Directorate, Universitas Gadjah Mada (UGM), Indonesia, for funding (RTA Project No. 3759) this study. The authors are also thankful to the Faculty of Veterinary Medicine, UGM, for providing the necessary facilities for this study.

\section{Competing Interests}

PT. Tekad Mandiri Citra, Indonesia, provided the drug free of cost for this study. However, it does not affect the study and publication at any stage.

\section{Publisher's Note}

Veterinary World remains neutral with regard to jurisdictional claims in published institutional affiliation.

\section{References}

1. Fancher, C.A., Zhang, L., Kiess, A.S., Adhikari, P.A., Dinh T.T.N. and Sukumaran, A.T. (2020) Avian pathogenic Escherichia coli and Clostridium perfringens: Challenges in no antibiotics ever broiler production and potential solutions. Microorganism, 8(10): 1533.

2. Djeffal, S., Mamache, B., Elgroud, R., Hireche, S. and Bouaziz, O. (2018) Prevalence and risk factors for Salmonella spp. Contamination in broiler chicken farms and slaughterhouses in the Northeast of Algeria. Vet. World, 11(8): 1102-1108.

3. Elbadawy, M. and Aboubakr, M. (2017) Efficacy of Trisin ${ }^{\circledR}$ (a new combination of sulfadiazine, trimethoprim, and erythromycin) in comparison with Baytril ${ }^{\circledR}$ and Tylan soluble ${ }^{\circledR}$ against Mycoplasma gallisepticum infection in broiler chickens. World J. Pharm. Pharm. Sci., 6(1): 150-161.

4. Nisha, A.R. (2008) Antibiotic residues-a global health Hazard. Vet. World, 1(12): 375-377.

5. Sattar, S., Hassan, M.M., Islam, S.K.M., Alam, M., Faruk, M.S.A., Chowdhury, S. and Saifuddin, A.K.M. (2014) Antibiotic residues in broiler and layer meat in Chittagong district of Bangladesh. Vet. World, 7(9): 738-743.

6. Li, J., Hao, H., Cheng, G., Wang, X., Ahmed, S., Shabbir, M.A.B., Liu, Z., Dai, M. and Yuan, Z. (2020) The effects of different enrofloxacin dosages on clinical efficacy and resistance development in chickens experimentally infected with Salmonella Typhimurium. Sci. Rep., 7(1): 11676.

7. Trouchon, T. and Lefebvre, S. (2016) A review of enrofloxacin for veterinary use. Open J. Vet. Med., 6(2): 40-58.

8. Gbylik-Sikorska, M., Posyniak, A., Sniegocki, T., Sell, B., Gajda, A., Sawicka, A. and Zmudzki, J. (2016) Influence of enrofloxacin traces in drinking water to doxycycline tissue pharmacokinetics in healthy and infected by Mycoplasma gallisepticum broiler chickens. Food Chem. Toxicol., 90(2): 123-129.

9. Farran, M.T., Ellakany, H.F., Shaib, H.A. and Majed, H.M. (2018) Evaluation of Antibiotics to control Mycoplasma gallisepticum in broiler breeder chickens. Poult Fish Wildl Sci., 6(1): 1-6.

10. Sargeant, J.M., Novy, A., Logue, C.M., Nicolds, J. and Winder, C. (2018) The Efficacy of Antibiotics to Prevent Collibacilosis in Broiler Poultry: A Protocol for a Systematic Review and Network Meta-analysis. Iowa University, Digital Repository, Iowa. Available from: https://www. core.ac.uk/download/pdf/212844365.pdf. Retrieved on 15-12-2021.

11. Antunes, N.T., Assunção, P., Poveda, J.B. and Tavío, M.M. (2015) Mechanisms involved in quinolone resistance in 
Mycoplasma mycoides subsp. capri. Vet. J., 204(3): 327-332.

12. Huang, Z., Wu, Y., Zhou, Z., Xia, X., Gu, Z., Cai, Q., Shen, Z., Yang, H. and Ding, H. (2019) Pharmacokinetic and pharmacodynamic integration and resistance analysis of tilmicosin against Mycoplasma gallisepticum in an in vitro Dynamic Model. Front. Pharmacol., 10(6): 670.

13. Mitchell, S.M., Ullman, J.L., Teel, A.L. and Watts, R.J. (2015) Hydrolysis of amphenicol and macrolide antibiotics: Chloramphenicol, florfenicol, spiramycin, and tylosin. Chemosphere, 134(9): 504-511.

14. Luby, E.M., Moorman, T.B. and Soupir, M.L. (2016) Fate and transport of tylosin-resistant bacteria and macrolide resistance genes in artificially drained agricultural fields receiving swine manure. Sci. Total Environ., 550(3): 1126-1133.

15. Fitriana, I., Chotimah, A.C., Wijayanti, A.D., Purwandari Y.K. and Pratama, A.M. (2020) Antibiotics combination effects of tylosin and enrofloxacin on liver and renal functions of broiler. IJVS, 1(1): 24-27.

16. Patriana, U., Werdiningsih, S., Bintang, S. and Mucharini, H. (1997) Metode Analisis Residu Obat Hewan. Balai Pengujian Mutu Obat Hewan, Indonesia. p78-81.

17. Sowjanya, S. and Devadasu, C. (2018) Development of RP-HPLC method for the simultaneous quantitation of levamisole and albendazole: Application to assay validation. Int. J. Anal. Chem., 2018(7): 5746305.

18. Haag, G., Marin, G.H. and Errecalde, J. (2016) Quantification of residual enrofloxacin and ciprofloxacin in feathers of broiler chickens by high-performance liquid chromatography-fluorescence after oral administration of the drugs. J. Adv. Pharm. Technol. Res., 7(1): 2-5.

19. Lee, H.C., Chen, C.M., Wei, J.T. and Chiu, H.Y. (2018) Analysis of veterinary drug residue monitoring results for commercial livestock products in Taiwan between 2011 and 2015. J. Food Drug Anal., 26(2): 565-571.

20. Widiastuti, R. (2008) Residu enrofloksasin dan siprofloksasin pada ayam pedaging pasca pencekokan enrofloksasin. JITV, 13(2): 150-154.

21. Taleuzzaman, M. (2018) Limit of blank (LOB), limit of detection (LOD), and limit of quantification (LOQ). Organic Med. Chem. IJ., 7(5): 555722.

22. Batrawi, N., Wahdan, S. and Al-Rimawi, F. (2017) A validated stability-indicating HPLC method for simultaneous determination of amoxicillin and enrofloxacin combination in an injectable suspension. Sci. Pharm., 85(6): 1-8.

23. Moudgil, P., Bedi, J.S., Aulakh, R.S., Gill, J.P.S., and Kumar, A. (2019) Validation of HPLC multi-residue method for determination of fluoroquinolones, tetracycline, sulphonamides and chloramphenicol residues in bovine milk. Food Anal. Methods, 12(2): 338-346.

24. Rasheed, C.M., Fakhre, N.A. and Ibrahim, M. (2017) Simultaneous determination of enrofloxacin and tylosin in chicken samples by derivative spectrophotometry. Arab $J$. Sci. Eng., 42(7): 4453-4463.

25. Ghanem, M. and Abu-Lafi, S. (2015) Development and validation of RP-HPLC method for the simultaneous determination of trimethoprim, sulfadimidine sodium and tylosin tartrate in injectable solution formulation. J. App. Pharm. Sci., 5(1): 94-98.

26. Karademir, U., Boyacioglu, M., Kum, C. and Sekkin, S. (2015) Comparative pharmacokinetics of enrofloxacin, danofloxacin and marbofloxacin following intramuscular administration in sheep. Small Rumin. Res., 133(9): 108-111.

27. Anacleto, S.D.S., Teixeira, L.S., Borges, M.M.C., Moraes, C.T., Borges, W.D.S., Pereira, A.C. and Borges, K.B. (2018) A simple and rapid HPLC method for the multidetermination of enrofloxacin, ciprofloxacin, and oxytetracycline in raw materials and veterinary pharmaceutical formulations. Curr. Pharm. Anal., 14(4): 397-404.

28. Yaneva, Z., Georgieva, N., Koinarski, V. and Petrova, D. (2015) Rapid RP HPLC method with PDA detection for tylosin determination in liquid samples. Trakia J. Sci. Ser. Biomed., 13(2): 309-314.

29. Hakim, L. (2011) Farmakokinetik. Bursa Ilmu, Yogyakarta.

30. Europe Medicines Agency. (2019) ICH Guideline M10 on bioanalytical Method Validation, Step 2b. Website. Available from: https://www.ema.europa.eu/en/documents/scientific-guideline/draft-ich-guideline-m10-bioanalytical-method-validation-step-2b_en.pdf. Retrieved on 01-12-2021.

31. Chakravarthy, V.A., Sailaja, B.B.V. and Kumar, A.P. (2015) Stability indicating RP-HPLC method for simultaneous estimation of enrofloxacin and its degradation products in tablet dosage forms. J. Anal. Methods Chem., 2015(1): 735145 .

32. Lindholm, J. (2004) Development and Validation of HPLC Methods for Analytical and Preparative Purposes. Dissertation, ACTA Universitas Upsaliensis, Uppsala, Sweden. p34-39.

33. Anwar, S. and Khan, P.M.A. (2020) Stability indicating RP-HPLC method for estimation of two synthetic antibiotics, amoxicillin and enrofloxacin, simultaneously. IJPSR, 11(1): 204-211. 